\title{
The first Sinomastodon (Gomphotheriidae, Proboscidea) skull from the Quaternary in China
}

\author{
WANG Yuan ${ }^{1,2^{*}}$, JIN ChangZhu ${ }^{1}$, DENG ChengLong ${ }^{3}$, WEI GuangBiao ${ }^{4} \&$ YAN YaLing ${ }^{1}$ \\ ${ }^{1}$ Key Laboratory of Evolutionary Systematics of Vertebrates, Institute of Vertebrate Paleontology and Paleoanthropology, Chinese Academy of \\ Sciences, Beijing 100044, China; \\ ${ }^{2}$ Department of Geosciences and Don Sundquist Center of Excellence in Paleontology, East Tennessee State University, Johnson City, \\ TN 37614, USA; \\ ${ }^{3}$ State Key Laboratory of Lithospheric Evolution, Institute of Geology and Geophysics, Chinese Academy of Sciences, Beijing 100029, China; \\ ${ }^{4}$ Chongqing Three Gorges Institute of Paleoanthropology, China Three Gorges Museum, Chongqing 400015, China
}

Received April 6, 2012; accepted September 26, 2012

\begin{abstract}
The first Sinomastodon (Gomphotheriidae, Proboscidea) skull of the Early Pleistocene, collected from the Renzidong Cave deposits in Anhui Province, Eastern China, is described here as S. jiangnanensis sp. nov. As the only brevirostrine trilophodont gomphotheriid known from the Old World, Sinomastodon was mainly indigenous to China from the Early Pliocene to the Pleistocene. Compared with a few single Pleistocene teeth previously found in China, S. jiangnanensis sp. nov. is represented by a relatively complete skull, mandible and dentition, which is the first discovery of a Quaternary Sinomastodon skull from China. With a brevirostrine, elephant-like skull, no lower tusks, and simple bunodont and trilophodont intermediate molars, the new species is morphologically distinct from other gomphotheres and should belong to the genus Sinomastodon. The new species is more progressive than $S$. hanjiangensis and the Pliocene type species $S$. intermedius in its skull and mandible morphology, but is evidently more primitive than the Pleistocene S. yangziensis in its molar morphology. The faunal analysis suggests that the emergence of $S$. jiangnanensis sp. nov. in Jiangnan area and its southward migration may have been related to a cooling event at the beginning of the Quaternary in Eastern China.
\end{abstract}

Gomphotheriidae, Sinomastodon, China, Renzidong Cave, Early Pleistocene

Citation: Wang Y, Jin C Z, Deng C L, et al. The first Sinomastodon (Gomphotheriidae, Proboscidea) skull from the Quaternary in China. Chin Sci Bull, 2012, 57: 4726-4734, doi: 10.1007/s11434-012-5519-y

Gomphotheriidae is considered as the main clade of the mastodons and was one of the most successful groups of Proboscidea due to its wide geographic distribution across all continents except Antarctic and Australia, from the Early Miocene to the Late Pleistocene [1]. Early members of Gomphotheriidae were characterized by long jaws that progressively evolved into the short-jawed types found in both the Old and New World.

Sinomastodon is the only brevirostrine trilophodont gomphotheriidae known from the Old World [1]. A reconstruction of Sinomastodon was erected by Tobien, Chen and $\mathrm{Li}$ in 1986 [2] on the basis of the Early Pliocene species

*Corresponding author (email: xiaowangyuan@ivpp.ac.cn)
Mastodon intermedius, discovered in 1937 by Teilhard and Trassaert [3] in the Yushe Basin, Shanxi Province, China. The genus Sinomastodon includes 3 known species that were indigenous primarily to China from the Early Pliocene to Pleistocene. Remains of the Early Pliocene S. intermedius (genotype) found in the Yushe Basin of Shanxi Province (Figure 1, locality 1), include the mandibles and molars [2-4]. Remains for the Late Pliocene S. hanjiangensis, including skull, mandible, molars and postcranial skeleton, have been discovered from the Hanzhong Basin, Shaanxi Province and the Hengduan Mountains (Figure 1, locality 2-6) [5-10]. The first discovery of Sinomastodon skull in $S$. hanjiangensis reveals its elephant-like cranium and bunodont molars. Additionally, isolated teeth have been discovered in 


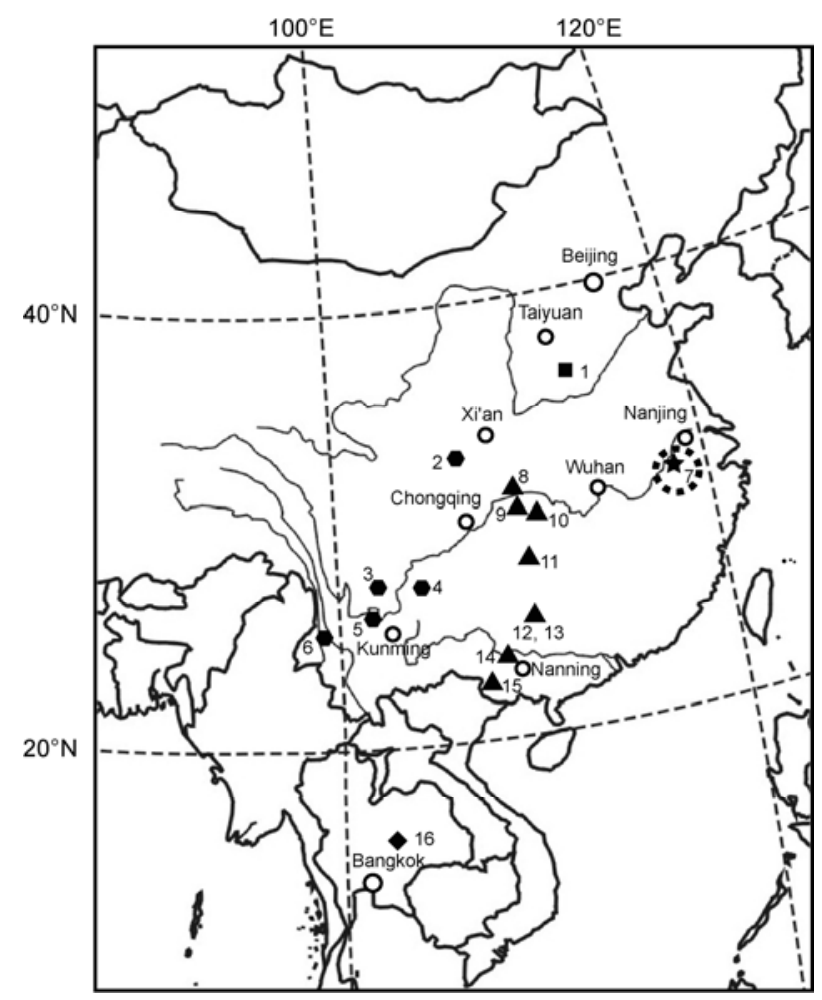

Figure 1 Map showing the Sinomastodon fossil sites. The Early Pliocene (S. intermedius) $\mathbf{m}: 1$ Yushe Basin, Shanxi Province [2-4]; The Late Pliocene (S. hanjiangensis) 2 Hanzhong Basin, Shaanxi Province [5,6], 3 Yanyuan, Sichuan Province [7,8], 4 Zhaotong, Yunnan Province [10], 5 Yongren, Yunnan Province [9], 6 Baoshan, Yunnan Province [8]; The early Early Pleistocene (S. jiangnanensis sp. nov.) 7 : Renzidong Cave, Anhui Province; The Early Pleistocene (S. yangziensis) $\boldsymbol{\Delta}$ : 8 Longgupo Cave in Wushan County, Chongqing [11,14], 9 Longgudong Cave in Jianshi County, Hubei Province [17,18], 10 Wufeng, Hubei Province [13,21], 11 Dongpaoshan, Baojin County, Hunan Province [19], 12 Liucheng Gigantopithecus Cave, Guangxi [15], 13 Bijiashan in Liuzhou, Guangxi [20], 14 Jiaoshan in Wuming, Guangxi [22], 15 Sanhe Cave in Chongzuo, Guangxi [16]; The Middle Pleistocene (Sinomastodon sp. nov.) $\diamond: 16$ North Thailand [23].

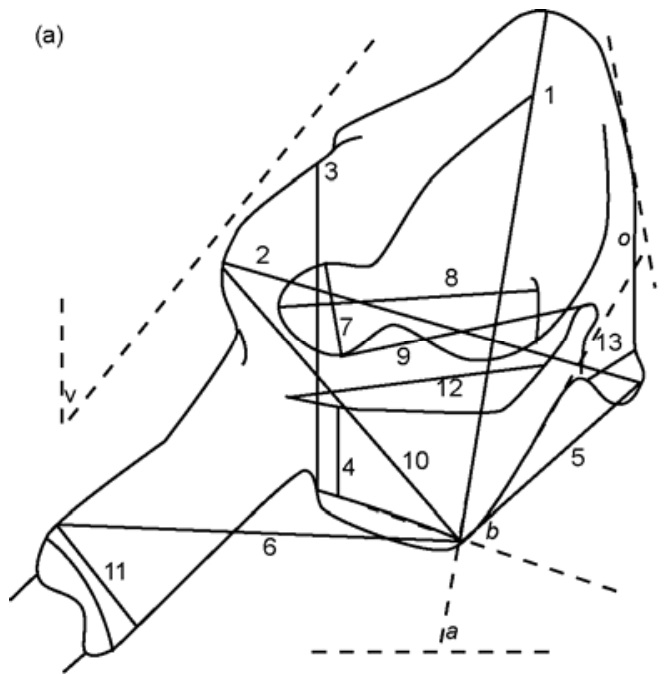

cave and fissure deposits of South China and identified as $S$. yangziensis from the Early Pleistocene [11-22] (Figure 1, locality 8-15). Recently, several molar fossils have been uncovered from sandpits of a secondary river terrace in North Thailand (Figure 1, locality 16) and tentatively assigned as Sinomastodon sp. B [23], which appears to date to be the Middle Pleistocene.

The Renzidong Paleolithic site (Figure 1, locality 7) discovered in 1998 is located near the south bank of the Yangtze River in Fanchang County, Anhui Province, Eastern China. This location lies in the transitional zone between the Palaearctic and Oriental zoogeographical regions. Systematic excavations of the cave have yielded numerous mammalian remains in association with stone and bone artifacts. According to the faunal analysis, the Renzidong fauna, estimated to be the early Early Pleistocene [24,25], is of rather archaic characteristics in the Quaternary faunas and more primitive than Longgupo fauna and Liucheng Gigantopithecus fauna. Preliminary paleomagnetic dating of the Renzidong Cave sediments shows that the fossil-bearing layers 3-7 are of a normal polarity, which roughly corresponds to the Reunion normal polarity subchron in terms of the biochronology and the rapid nature of the Renzidong Cave sedimentary sequence. Hence, the age of the strata yielding Sinomastodon in Renzidong Cave is dated to be 2.14-2.15 Ma BP. Details of the paleomagnetic dating will be addressed elsewhere.

The most conspicuous large mammalian remains from Renzidong Cave include the complete Sinomastodon skull, mandible, molars and postcranial materials. The molars (M3/m3) have been assigned as $S$. yangziensis in a preliminary report [24]. This first discovery of Sinomastodon skull from the Quaternary in China has significant implications for discussing the evolution, dispersion and related paleoecological variation of Sinomastodon during the Quaternary.

We follow Ferretti [26], Lister [27] and Tassy [28] (Figure 2(a)) for the skull measurements, Ferretti [26] and Tong

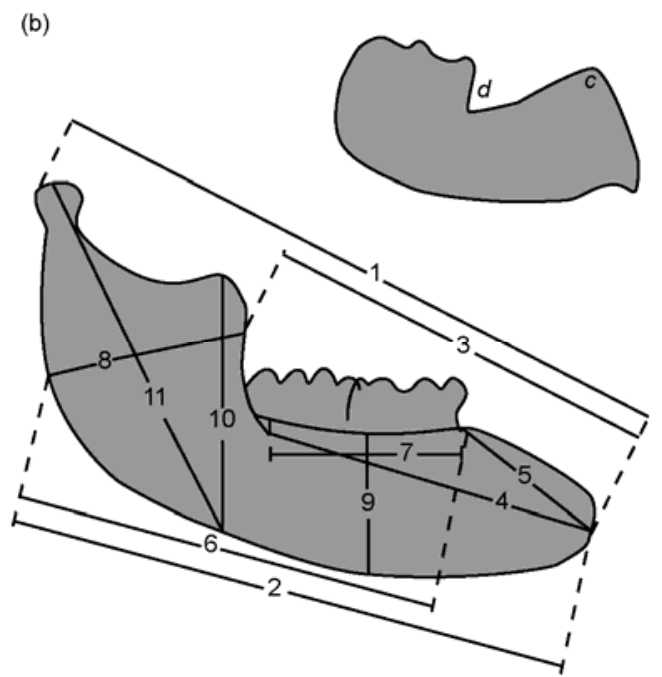

Figure 2 The schematic sketch of measurements of Sinomastodon skull (a) and mandible (b) (For details see Tables 1 and 2). 
[29] (Figure 2(b)) for the mandible measurements, and Tassy [28] (Figure 3) for gomphotheriid molar nomenclature.

\section{Systematic paleontology}

\section{Order Proboscidea Illiger, 1811}

Suborder Elephantiformes Tassy, 1988

Family Gomphotheriidae Hay, 1922

Subfamily Sinomastodontinae subfam. nov.

Genus Sinomastodon Tobien, Chen and Li, 1986

Type species. Sinomastodon intermedius (Teilhard and Trassaert, 1937).

Included species. Sinomastodon hanjiangensis Tang and Zong, 1987; Sinomastodon jiangnanensis sp. nov.; Sinomastodon yangziensis (Chow, 1959); Sinomastodon sp. nov.

Stratigraphic range. The Early Pliocene to possibly the Middle Pleistocene.

Amended diagnosis. Medium to large trilophodont gomphotheriid with high-domed cranium, brevirostrine mandible and no lower permanent incisors. Cranium is obviously compressed anterior-posteriorly compared to typical long-jawed Gomphotheriidae (e.g. Gomphotherium). The orbit locates anteriorly. Premaxilla shrinks. Molar alveoli extends slightly anterior-inferiorly. Mandibular symphysis

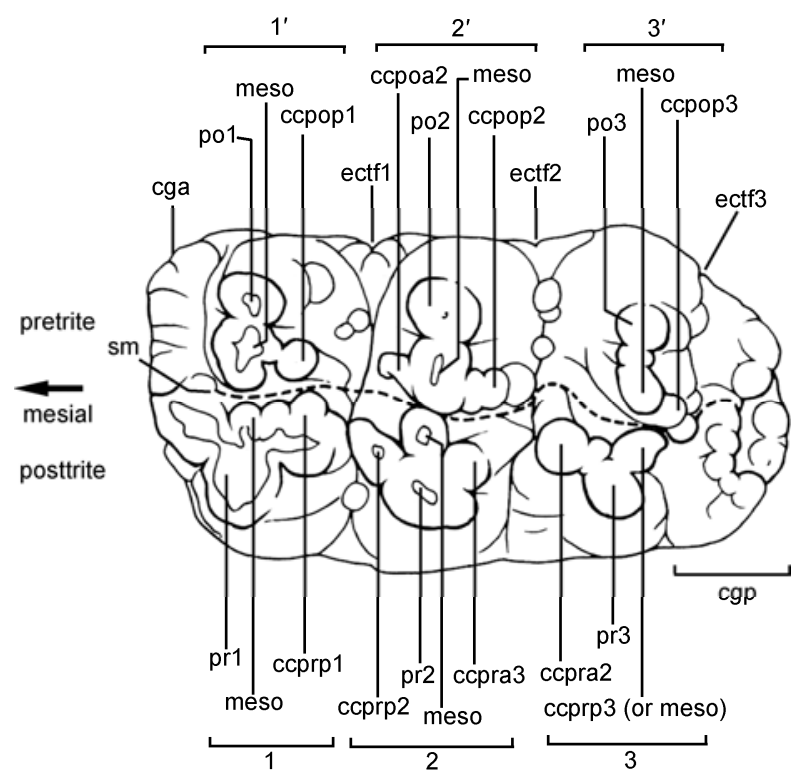

Figure 3 The schematic sketch of crown structure of gomphotheres (left M2) from Tassy [28]. 1, 2, 3, pretrite halves of the 1st, 2nd, and 3rd lophs; 1', 2', 3', posttrite halves of the 1st, 2nd, and 3rd lophs; ccpoa, anterior posttrite central conule of each loph; ccpop, posterior posttrite central conule of each loph; ccpra, anterior pretrite central conule of each loph; ccprp, posterior pretrite central conule of each loph; cga, anterior cingulum; cgp, posterior cingulum; ectf, ectoflexus of each interlophs; meso, mesoconelet of each half-loph; po, main cusp of posttrite of each loph; pr, main cusp of pretrite of each loph; sm, median sulcus. is reduced with narrow gutter, while the mandibular angle is rounded. The upper tusks, with an almost circular transverse section, are slightly curved upwards, with no enamel band. The bunodont molars are characterized by the clear median sulcus and trilophodont intermediates (DP4/dp4, M1/m1, M2/m2). M3 exhibits 5 or 6 lophs, while m3 exhibits 5-8 lophids. The pretrite half-lophs/lophids are subdivided into the main cusps and mesoconelets. The worn surfaces show trefoil pattern. The secondary trefoil and cement in transverse valleys are usually absent except in the progressive species. The anterior cingulum is present while the posterior and lateral cingula become gradually weaker. The entocuneiform is normally missing.

Sinomastodon jiangnanensis sp. nov. (Figures 4 and 5)

Synonym. Sinomastodon yangziensis (Chow, 1959), Jin and Liu (2009). Paleolithic Site-the Renzidong Cave, Fanchang, Anhui Province. Beijing: Science Press. 283-286 [24].

Holotype. One relatively intact skull and mandible with DP4/dp4 and M1/m1 (IVPP V 18221).

Paratype. One right M3 (V14011.02) and one right m3 (V14011.03).

Hypodigm. Seven fragments of upper adult tusks (V18221. 11-17), one left M3 (V18222.01), two M2

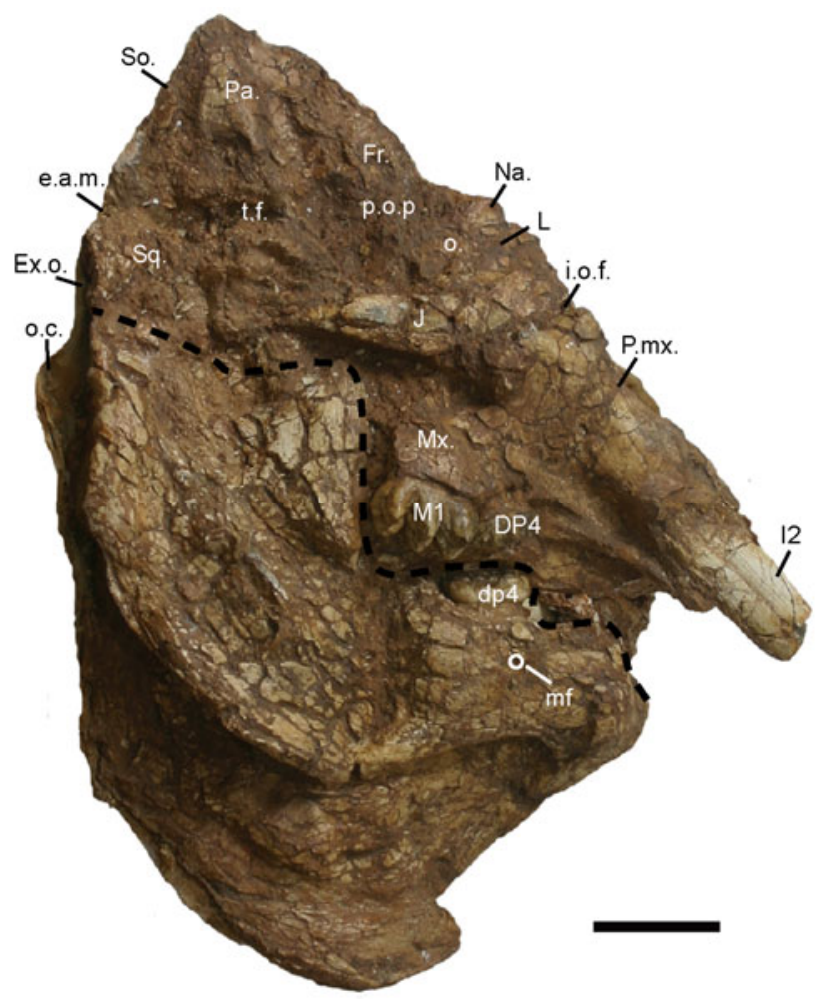

Figure 4 The skull and mandible of Sinomastodon jiangnanensis sp. nov. (IVPP V 18221), lateral view. Abbreviations: e.a.m. (secondary) external auditory meatus; Ex.o., exoccipital; Fr., frontal; i.o.f., infraorbital foramen, J, jugal; L, lachrymal; mf, mental foramen; Mx., maxilla; Na., nasal; o., orbit; o.c., occipital condyle; P.mx., premaxilla; p.o.p, posterior orbit process; Pa., parietal; So., supraoccipital, Sq., squamosal; t.f., temporal fossa. Scale: $10 \mathrm{~cm}$. 


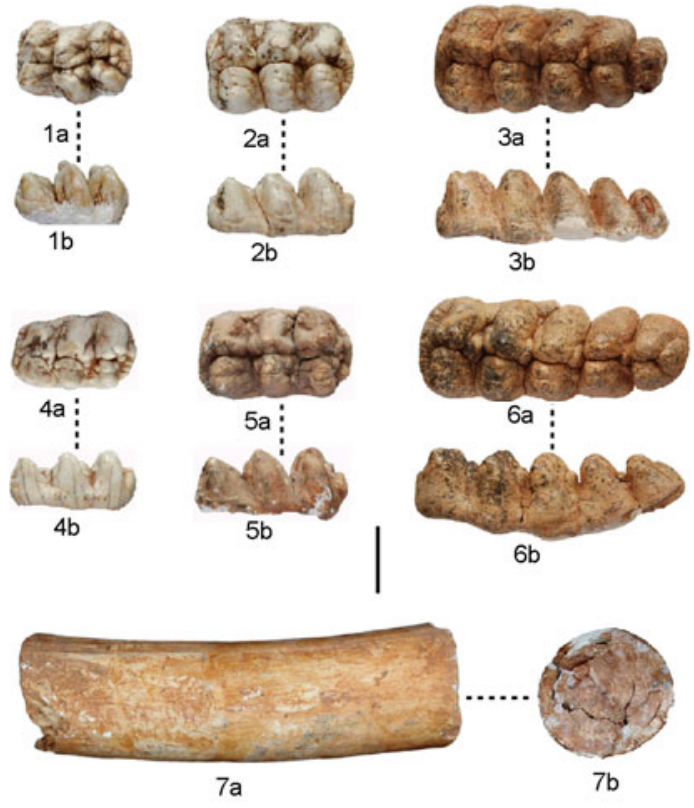

Figure 5 The molars and fragmentary I of Sinomastodon jiangnanensis sp. nov. 1, right M1 (V18222.04); 2, right M2 (V18222.02); 3, right M3 (V14011.02); 4, right $\mathrm{m} 1$ (V18222.08); 5, right $\mathrm{m} 2$ (V18222.07); 6, right m3 (V14011.03): 1a-6a, occlusal view; 1b-3b, labial view; 4b-6b, lingual view; 7, fragment of upper incisor (V18221. 11): 7a, lateral view; 7b, cross section. Scale: $5 \mathrm{~cm}$.

(V18222.02, 03), two M1 (V18222.04, 05), one left m3 (V18222.06), one right $\mathrm{m} 2$ (V18222.07), one right $\mathrm{m} 1$ (V18222.08), one fragmentary $\mathrm{m} 1$ (V18222.09) and one fragmentary m2 (V18222.10).

Type locality and horizon. Layer 3 to 7, the upper part of the Renzidong Cave, Fanchang County, Anhui Province, Eastern China.

Geological age. The early Early Pleistocene (2.14-2.15 Ma BP).

Etymology. Specific name is derived from Chinese "Jiangnan", meaning south of Yangtze River.

Diagnosis. Relatively larger size than $S$. intermedius, $S$. hanjiangensis and S. yangziensis. Cranium high, occipital and frontal region shortened, maxilla deepened and premaxilla steepened. Mandible with short symphysis, articular process high, coronoid process becomes more anterior, horizontal ramus deepened. M3 is characterized by 5 lophs while $\mathrm{m} 3$ is characterized by 5 lophids and an isolated talonid. The posterior pretrite central conule develops into an isolated cusp. No cement in transverse valleys. The anterior cingulum is developed while the posterior and lateral cingula become obviously degenerated.

Measurements. See Tables 1-3.

Description. Due to taphonomic breakage and compression, the skull can be observed only in the lateral view.

The outline of the cranial vault is regularly convex. The skull vertex is on the perpendicular passing just behind the jugal. The occipital and frontal regions are shortened. The line of the exoccipital is relatively steep. The upper border of the external nares is located just above the middle of the orbit. The lachrymal is located at the anterior border of the orbit, whose posterior margin is just at the front of DP4.

Table 1 The cranial measurements of Sinomastodon jiangnanensis sp. nov. (IVPP V 18221) (mm) ${ }^{\mathrm{a})}$

\begin{tabular}{|c|c|c|c|c|c|c|c|c|c|}
\hline Measurements & 1 & 2 & 3 & 4 & 5 & 6 & 7 & 8 & 9 \\
\hline Skull & 394 & 227 & 241 & 115 & 277 & 291 & 65 (ca.) & 234 (ca.) & 287 (ca.) \\
\hline Measurements & 10 & 11 & 12 & 13 & 14 & 15 & 16 & 17 & \\
\hline Skull & 242 & 88 & 276 (ca.) & 74 (ca.) & $70^{\circ}$ & $35^{\circ}$ & $115^{\circ}$ & $35^{\circ}$ & \\
\hline
\end{tabular}

a) For the measurement methods see Figure 2(a); 1, cranial height from top of cranium to the pterygoid process; 2, cranial length from preorbital process to occipital condyle; 3 , facial height taken at the anterior grinding tooth; 4 , height of the maxilla ventral to zygomatic process; 5 , length of basicranium from occipital condyles to pterygoid process; 6 , facial length from tip of the rostrum to pterygoid process; 7 , height of the orbit; 8 , length of the orbitotemporal fossa from the squamosal to the anterior border of the orbit; 9 , mid-cranial length from the external auditory meatus to the ventral border of the orbit; 10 , mid-cranial height from the pterygoid process to the dorsal border of the orbit; 11, maximum dorso-ventral diameter of tusk alveoli; 12 , length of zygomatic arch; 13, greatest length of occipital condyle; 14, Angle between dorso-ventral axis of cranium and the horizontal ( $\angle a)$; 15 , Angle between molar alveoli and occipital condyle $(\angle b) ; 16$, Angle between occipital and basicranial planes $(\angle o) ; 17$, Angle between tusk alveoli and vertical line $(\angle v)$. ca., estimate.

Table 2 The mandible measurements of Sinomastodon jiangnanensis sp. nov. (IVPP V 18221) (mm) ${ }^{\mathrm{a})}$

\begin{tabular}{lcrrrrrr}
\hline Measurements & 1 & 2 & 3 & 4 & 5 & 7 & 3 \\
\hline Mandible & 556 (ca.) & 486 & 347 & 264 & 116 & 162 \\
\hline \hline Measurements & 8 & 9 & 10 & 413 & 12 \\
\hline Mandible & 240 & 115 & 333 & 416 (ca.) & $120^{\circ}$ & $90^{\circ}$ \\
\hline
\end{tabular}

a) For the measurement methods see Figure 2(b); 1, Length: most aboral margin of condyle-infradentale; 2, Length: gonion caudale-infradentale; 3, Length: infradentale-most oral point of the anterior margin of the ascending ramus; 4, Length: infradentale-anterior origin of ascending ramus; 5, Length: infradentale-oral border of the anterior grinding tooth; 6, Length: gonion caudale-oral border of the anterior grinding tooth; 7, Length: oral border of the anterior grinding tooth-anterior origin of ascending ramus; 8, Length: gonion caudale-most oral point of the anterior margin of the ascending ramus; 9 , height of the mandible body at midpoint of the cheektooth row; 10, Oral height of ascending ramus: gonion ventrale-corion; 11 , aboral height of ascending ramus: gonion ventrale-heighest point of condyle; 12, angle between the front wall and the edge of the alveolus $(\angle c)$; 13, angle between the mandibular body and the ramus $(\angle d)$. ca., estimate. 
Table 3 Molar measurements of Sinomastodon jiangnanensis sp. nov. (mm $)^{\mathrm{a})}$

\begin{tabular}{|c|c|c|c|c|c|c|c|c|c|}
\hline & No. & $\mathrm{L}$ & $\mathrm{W}$ & $\mathrm{H}$ & $\mathrm{W} 1$ & $\mathrm{~W} 2$ & W3 & W4 & W5 \\
\hline Right M3 & V14011.02 & 176.1 & 83.1 & 64.1 & 83.1 & 82.6 & 79.6 & 69.5 & 44.3 \\
\hline Left M3 & V18222. 01 & - & 83.4 & 62.8 & 83.4 & 82.3 & 76.8 & 65.3 & - \\
\hline Left M2 & V18222. 03 & 114.2 & 72.2 & 47.4 & 70.3 & 72.2 & 71.8 & - & - \\
\hline Right M1 & V18222. 04 & 87.3 & 60.1 & 43.3 & 58.1 & 60.1 & 59.1 & - & - \\
\hline Left M1 & V18222. 05 & 86.2 & 60.4 & 34.8 & 59.8 & 60.4 & 60.3 & - & - \\
\hline Right m3 & V14011.03 & 204.5 & 80.1 & 60.6 & 78.7 & 80.1 & 75.4 & 70.6 & 59.1 \\
\hline Left m3 & V18222. 06 & 201.6 & 80.6 & 60.2 & 80.5 & 80.6 & 75.9 & 72.1 & 62.1 \\
\hline Right m2 & V18222. 07 & 117.6 & 69.1 & 57.3 & 67.4 & 69.1 & 68.8 & - & - \\
\hline Right m1 & V18222. 08 & 95.2 & 60.2 & 47.3 & 49.6 & 56.6 & 60.2 & - & - \\
\hline Left m1 & V18222. 09 & - & 60.8 & 48.4 & - & 57.5 & 60.8 & - & - \\
\hline Left $\mathrm{m} 2$ & V18222. 10 & - & 64.6 & 42.1 & - & - & 64.6 & - & - \\
\hline
\end{tabular}

a) L, length; W, width; H, height; W1, width of the first loph/lophid.

The posterior orbit process is robust. The temporal fossa is broad. The zygomatic arch is well developed with a relatively high position. The posterior orbit process is robust. The temporal fossa is relatively large. The zygomatic arch is obviously developed with higher location. The maxilla is deepened. Molar alveoli extend slightly anterior-inferiorly. The infraorbital foramen is present but the supraorbital foramen absent. There is only one infraorbital foramen while the supraorbital foramen is missing. The premaxilla is steepened. The proximo-distal axis of the tusk alveoli is parallel to the plane of the forehead. Occipital condyle is well developed.

Mandible is articulated to the skull. From the lateral view, horizontal ramus is deepened, ascending ramus is slightly inclined backward, the articular region is elevated, and the coronoid process is lengthened. The mandibular angle is rounded and slightly caudally protruding. Rostrum is shortened and tuskless. The mental foramen is located beneath the anterior margin of dp4.

Upper incisor curves upwards slightly and has no enamel band. The transverse section is almost circular, with a maximum diameter of $110 \mathrm{~mm}$ and a minimum diameter 85 $\mathrm{mm}$.

Bunodont molars with the clear median sulcus and trilophodont intermediates (M1/m1, M2/m2). The trefoil pattern is developed on the pretrite while the secondary trefoil is almost absent on the posttrite. The pretrite and posttrite are basically parallel and almost intersect orthogonally with the median sulcus. The cement in transverse valleys is absent. The anterior cingulum is present while the posterior and lateral cingula become obviously weaker. The ectoflexus are present among the interlophs/interlophids.

On M1/M2, the crown is rectangular. The mesoconelet, anterior/posterior central conule of the pretrite are well developed. The posterior pretrite central conule of the third loph develops into a large cusp. On the posttrite side, the main cusp and mesoconelet are nearly equivalent in size, with the anterior/posterior posttrite central conule absent or very weak, except for the posterior posttrite central conule of the third loph which becomes a middle-sized cusp. The posterior talon is composed of a series of serrated cingula.

The M3 is composed of 5 lophs and a weak talon. The crown becomes gradually narrower from front to back. On the first 4 lophs, the mesoconelets and anterior central conules of the pretrite are well developed while the posterior posttrite central conules become large cusps and inflates to the posttrite side. The mesoconelet of the posttrite is separated into several small cones while the anterior/posterior posttrite central conule are basically missing. The simple fifth loph is composed of 2 main cusps. The talon is composed of small cones, attaching to the posterior wall of the fifth loph.

On $\mathbf{m} \mathbf{1} / \mathbf{m} \mathbf{2}$, the crowns are both rectangular. The mesoconelet and anterior central conule of the pretrite are well developed and the posterior pretrite central conule is an isolated cusp. The mesoconelet of the posttrite is well developed and divided into several small cones while the anterior/posterior posttrite central conule are basically missing. The posterior talonid is composed of a series of serrated cingulum. There is a small cusp between the third lophid and talonid on both pretrite and posttrite of $\mathrm{m} 2$.

The $\mathbf{m} \mathbf{3}$ is composed of 5 lophids and a talonid. The crown becomes gradually narrower from front to back and the median sulcus is slightly curved to the labial side. On the first 4 lophs, the mesoconelet of the pretrite is well developed and almost the same size as the main cusp. The anterior pretrite central conule becomes ridge shaped. The posterior pretrite central conule, nearly equivalent in size to the main cusp, becomes an isolated cusp and clearly inflates to the posttrite side. The mesoconelet of the posttrite is obviously larger than the main cusp and is separated into several small cones on the first and second lophids. On the third and fourth lophids, the mesoconelet of the posttrite is a single isolated cusp and is almost the same size as the main 
cusp. The anterior/posterior posttrite central conule are basically absent, except for a small cone on the posterior wall of the third and fourth lophids. The narrower fifth lophid is composed of a large main cusp and a small mesoconelet on both pretrite and posttrite. The talonid is composed of a single large cone, attaching to the posterior wall of the fifth lophid.

\section{Comparisons and discussion}

According to the updated systemactics of Proboscidea [1], the early members of family Gomphotheridae include the typical long-jawed forms, such as Gomphotheriinae, Amebelodontinae, Choerolophodontinae and Rhynchotheriinae. The progressive short-jawed gomphotheres occurred in the New World with one subfamily Cuvieroniinae containing 3 known genera: Cuvieronius, Stegomastodon and Haplomastodon. Sinomastodon is the only brevirostrine trilophodont gomphothere known from the Old World. Because of the massive skull and mandible differences between Sinomastodon and the typical long-jawed gomphotheres and the geographical differences between Sinomastodon and American Cuvieroniinae, here we erect a new subfamily, Sinomastodontinae subfam. nov.

The skull and mandible of Renzidong gomphothere are similar to those of elephantoid in having the following characteristics: high and anterior-posteriorly compressed cranium, deepened maxilla, steepened premaxilla, anteriorly located orbit, missing supraorbital foramen, mandible with short symphysis and no lower permanent incisors.

The typical long-jawed gomphotheres (e.g. Gomphotherium [30], Choerolophodon [31] and Platybelodon [32]) are obviously more primitive than the Renzidong remains in that they bear a flattened and elongated neurocranium, long premaxilla and developed lower incisors.

Rhynchotherium [33], the typical long-jawed trilophodont from North America, bears a slightly uplifted and compressed cranium, obviously shortened mandible symphysis and displays the transitional characteristics between long-jawed and short-jawed gomphotheres. The developed lower permanent incisors of Rhynchotherium indicate it is still more primitive than the Renzidong remains.
Here we adopt 6 skull and mandible quantitative indexes to explain the evolutionary grade of the Renzidong remains (Table 4). The skull and mandible morphology of Renzidong remains are most similar to those of $S$. intermedius, $S$. hanjiangensis, and the American Haplomastodon. All of these bear the transitional characteristics between longjawed trilophodont (e.g. Gomphotherium) and elephantoid (e.g. Mammuthus). However, the Renzidong remains appear more primitive than Haplomastodon and Mammuthus morphologically. For example, the molar alveoli slightly extend anterior-inferiorly on Renzidong remains, while on elephantoid, the molar alveoli obviously spread anteriorsuperiorly.

The upper incisor of the Renzidong remains curves upwards slightly and most closely resembles that of $S$. hanjiangensis. Comparing the upper incisors, the Renzidong remains are totally different from Gomphotherium [30] whose incisor curves significantly downward and American Stegomastodon/Haplomastodon [33] whose incisor is strongly curved upward.

Comparing molar aspects, Gomphotherium [2,30,34] and North American Rhynchotherium [32] appear to have more primitive molars than those from the Renzidong remains which exhibit the developed premolars, 4 lophs/lophids on $\mathrm{M} 3 / \mathrm{m} 3$, developed lateral cingula and the weak mesoconelets of the pretrite and posttrite. Further analysis indicated that Anancus, which bears tetralophodont intermediate molars, more lophs/lophids on $\mathrm{M} 3 / \mathrm{m} 3$ and the interlocking lophs/lophids structure [13], is more advanced than the Renzidong remains.

Although similarities are observed with the skull and mandible when comparing the Renzidong remains and American Cuvieroniinae, Cuvieroniinae is distinct from the Renzidong remains by having cement in transverse valleys and the isolated mesoconelet of the pretrite and posttrite [33]. Additionally, on some progressive types (e.g. Stegomastodon), there are 6 lophs/lophids on M3/m3, the developed secondary trefoil and plicate enamel (ptychodonty) [35].

The Renzidong remains should be assigned into the genus Sinomastodon, based on the following characteristics: elephant-like skull and mandible; bunodont molars with the clear median sulcus; trilophodont intermediates (M1/m1,

Table 4 Comparison of measurements of skull and mandible among Sinomastodon jiangnanensis sp. nov. and other related taxa ${ }^{\text {a) }}$

\begin{tabular}{|c|c|c|c|c|c|c|c|}
\hline & Measurements & $\begin{array}{c}\text { Sinomastodon } \\
\text { jiangnanensis sp. nov. }\end{array}$ & $\begin{array}{c}\text { S. intermedius } \\
{[2]} \\
\end{array}$ & $\begin{array}{c}\text { S. hanjiangensis } \\
{[6]}\end{array}$ & $\begin{array}{c}\text { Haplomastodon } \\
\text { [26] }\end{array}$ & $\begin{array}{c}\text { Gomphotherium } \\
{[30]}\end{array}$ & $\begin{array}{c}\text { Mammuthus } \\
\text { [27] }\end{array}$ \\
\hline \multirow{4}{*}{ Skull } & $\angle a$ & $70^{\circ}$ & - & $65^{\circ}$ & $75^{\circ}$ & $<60^{\circ}$ & $>75^{\circ}$ \\
\hline & $\angle b$ & $35^{\circ}$ & - & $30^{\circ}$ & $45^{\circ}$ & $<30^{\circ}$ & $>45^{\circ}$ \\
\hline & $\angle o$ & $115^{\circ}$ & - & $100^{\circ}$ & $95^{\circ}$ & $<90^{\circ}$ & $>120^{\circ}$ \\
\hline & $\angle v$ & $35^{\circ}$ & - & $40^{\circ}$ & $40^{\circ}$ & $>45^{\circ}$ & $<30^{\circ}$ \\
\hline \multirow{2}{*}{ Mandible } & $\angle c$ & $120^{\circ}$ & $140^{\circ}$ & $145^{\circ}$ & $130^{\circ}$ & $>145^{\circ}$ & $<100^{\circ}$ \\
\hline & $\angle d$ & $90^{\circ}$ & $100^{\circ}$ & $95^{\circ}$ & $95^{\circ}$ & $>120^{\circ}$ & $<90^{\circ}$ \\
\hline
\end{tabular}

a) For the measurement details see Figure 2 and Tables 1 and 2. 
$\mathrm{M} 2 / \mathrm{m} 2$ ); 5 lophs/lophids on M3/m3; the developed trefoil pattern on the pretrite and absence of cement in transverse valleys.

Considering the skull and mandible, the Renzidong remains appear more primitive than $S$. intermedius [2] and $S$. hanjiangensis [6], based on the observed higher cranium, compressed occipital, higher zygomatic arch, deepened maxilla, higher articular process, coronoid process extending more anteriorly, and deepened horizontal ramus.

Molars from the Renzidong remains are larger than Pliocene $S$. intermedius and $S$. hanjiangensis according to the size of $\mathrm{m} 3$, which is the most significant for identification of proboscidea (Figure 6). On the number of M3/m3 loph/ lophid, the Renzidong remains correspond to $S$. hanjiangensis with 5 lophs on M3 and 5 lophids plus alone small talonid on $\mathrm{m} 3$, and are more advancedthan $S$. intermedius with only 5 lophids on $\mathrm{m} 3$. In addition, the Renzidong remains are also more progressive based on the following molar traits: the posterior pretrite central conule becomes an isolated cusp and clearly inflates to the posttrite side; the mesoconelet of the posttrite separates into several small cones; the enamel pillars appear in the transverse valleys, and the obviously weaker lateral cingula are observed.

The Pleistocene species S. yangziensis is more advanced than Renzidong remains in having obviously smaller size (Figure 6), slender crown, 5 lophs on M3 with a talon of 2 pillars, 5 or 6 lophids on $\mathrm{m} 3$, more developed mesoconelet of the pretrite, a little cement in transverse valleys, more developed posterior posttrite central conule, weaker anterior cingulum and no lateral cingulum.

The Sinomastodon sp. B [23] from North Thailand is much more progressive than Renzidong remains in bearing obviously larger size (Figure 6), much more elongated crown, developed cement in transverse valleys, much weaker anterior cingulum, distinct increase of $\mathrm{M} 3 / \mathrm{m} 3 \mathrm{loph} /$ lophid and more developed posterior posttrite central conule. As the most advanced Sinomastodon by far, Sinomastodon sp. B appears to be a new species of the genus (Saegusa and Thasod, personal communications). Here Sinomastodon sp. B is revised as Sinomastodon sp. nov. provisionally and the

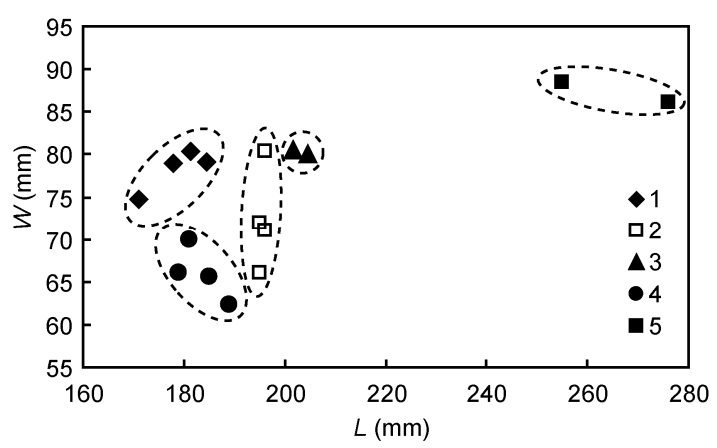

Figure 6 Comparison of $\mathrm{m} 3$ measurements within the genus Sinomastodon. 1, Sinomastodon intermedius [2-4]; 2, S. hanjiangensis [6,9]; 3, S. jiangnanensis sp. nov.; 4, S. yangziensis [14-16]; 5, Sinomastodon sp. nov. [23]. systematic details will be published elsewhere.

As stated above, the Sinomastodon remains from Renzidong Cave have been identified as $S$. jiangnanensis sp. nov. This taxon is more progressive than $S$. hanjiangensis and the Pliocene type species $S$. intermedius in its skull and mandible morphology, but is evidently more primitive than the Pleistocene S. yangziensis in its molar morphology.

\section{The speciation, dispersal and environment background of $S$. jiangnanensis sp. nov.}

According to the available data, Sinomastodon was primarily indigenous to China from the Early Pliocene to the Middle Pleistocene. The genus appears to have spread north from Yushe Basin, Shanxi, south to Chongzuo, Guangxi, west from Baoshan, Yunnan, and east to Fangchang, Anhui (Figure 1). The advanced species of Sinomastodon also appears sporadically in southeast Asia (e.g. Thailand).

During the Early Pliocene and Pleistocene, the Sinomastodon lineage experienced at least 4 Sinomastodon Speciation Events (SSE) in China, resulting in the emergence of $S$. intermedius (SSE1), S. hanjiangensis (SSE2), S. jiangnanensis sp. nov. (SSE3) and S. yangziensis (SSE4).

The Pliocene Sinomastodon remains have been distributed across North China and also have been found sporadically in the Hengduan Mountains Region. The species $S$. intermedius has been found in the Gaozhuang Formation from the Yushe Basin, Shanxi, and has been dated to the Early Pliocene (5.3-3.4 Ma BP) [12,36]. S. hanjiangensis has been unearthed in the Yangjiawan Formation from the Hanzhong Basin, Shaanxi[6] and from the Shagou Formation in the Hengduan Mountains [12], which corresponded to the Mazegou Formation, dating to the late Pliocene (3.4-2.6 Ma BP) [36]. For materials dating from the Quaternary, all Sinomastodon remains have been found in the south of Yangtze River and are considered as the typical elements of the Oriental realm. This paper focuses on the speciation, dispersal and environment background of $S$. jiangnanensis sp. nov. (SSE3).

Data comprising deep-sea records from the South China Sea [37] and the loess deposit sequence [38] indicate a serious climatic changes that occurred during the Early Pleistocene (2.58-2.14 Ma BP), characterized by cooling of the global climate, major growth of global ice, the emergence of the arctic icecap and the formation of the Bering Land bridge [39]. Since 2.58 Ma, East Asia experienced frequent and dramatic climate fluctuations resulting in the formation of stronger winter monsoons and increasing continental dryness, with the appearance of loess deposits and stiff grass vegetation indicating a cold and dry environment. The geological changes responsible for the rapid uplift of Tibetan are probably related to the above noted climate deterioration [40].

The evolution and migration of terrestrial mega-mam- 
mals mainly correlates to the changes of climate and environment. The severe climatic change during the early Early Pleistocene (2.58-2.14 Ma BP) corresponded to the Biological Event 6 [41], illustrated by the emergence of the Renzidong, Longdan or Houhecun faunas. This event is also called the lowest Equus layer event (the Equus eisenmannae LSD) $[42,43]$, named for the eastward spread of Equus from North America to Eurasia.

Based on the faunal analysis, the Renzidong fauna from the southern bank of the Yangtze River indicates a warm semi-arid and semi-humid forest-grassland environment. Evidently, this fauna has characteristics of a transitional zone with more typical northern types [24]. The large scale invasion of northern forms moving to the south implies a distinct cooling event at the beginning of the Quaternary, resulting in a southward migration of Sinomastodon to the Jiangnan area and the speciation of S. jiangnanensis sp. nov.

During the Early Pleistocene, the disappearance of Sinomastodon and other trilophodont gomphotheres in north China (e.g. Longdan fauna, Gansu [43] and Nihewan fauna (s.s.), Hebei $[44,45]$ ) and the Hengduan Mountains (e.g. Yuanmou Man fauna, Yunnan [24]) demonstrates that the trilophodont gomphotheres became extinct by the end of the Pliocene in north China and the Hengduan Mountains. This is closely related to the cooling event since $2.58 \mathrm{Ma}$. According to the faunal analysis, the Longdan fauna originates from the loess deposits implying a cold and dry environment [43], while the Nihewan fauna (s.s.) indicates a dry and cool grassland environment [24]. Conversely, the Yuanmou Man fauna are indicative of an open grassland dominated environment with a warm and dry climate [24]. Obviously, Sinomastodon is unfit for the two former environments. The absence of Sinomastodon in Yuanmou Man fauna suggests a possible relationship to the flourishing of Stegodon, besides the climate variation.

Noticeably, there is synchronization between the emergence of Sinomastodon jiangnanensis sp. nov. and 2 another proboscideans: Mammuthus meridionalis [46] and Stegodon huananensis [47]. At the beginning of Quaternary (2.58 Ma BP), Mammuthus meridionalis originated in north China while Sinomastodon and Stegodon migrated southward and gave birth to the new species. Detailed study will be required to determine any correlations involving synchronization of speciation among the 3 proboscideans discussed above.

\section{Conclusions}

(1) Sinomastodon jiangnanensis sp. nov. from the Renzidong Cave in Anhui of the early Early Pleistocene appears more progressive than the Pliocene $S$. intermedius and $S$. hanjiangensis mainly based on differences in skull and mandible morphology, but it is evidently more primitive than the younger $S$. yangziensis when comparing molar morphologies, thus reflecting the morphological transition of the genus from Neogene to Quaternary.

(2) The skull of Sinomastodon jiangnanensis sp. nov. is the first discovery of a Sinomastodon skull in China from the Quaternary. Renzidong fauna, situated in the transitional zone between the Palaearctic and the Oriental zoogeographical regions, implies a cooling event at the beginning of the Quaternary, resulting in a southward migration of Sinomastodon and the development of S. jiangnanensis sp. nov.

(3) Sinomastodon is the only brevirostrine trilophodont gomphothere known from the Old World, because of this a new subfamily is designated as Sinomastodontinae subfam. nov involving the single genus Sinomastodon.

We are thankful for the guidance and discussions provided by Profs. Zheng $J J$, Chen $G F, L i C K, X u Q Q$, Wang $N W, N i X J$ and Drs. Wang $S Q$, Saegusa H, Thasod Y. Many thanks go to the editors and anonymous reviewers for their instructions, Prof. Jim Mead improving the English draft, Mr. Sun $W S$ restoring the fossils and Mr. Wu G Z taking photos. This work was supported by the Chinese Academy of Sciences (KZCX2YW-159 and KZZD-EW-03), the National Natural Science Foundation of China (41072013, 41202017 and J0930007), the China Geological Survey (1212011220519 and 1212011120118), and the Key Laboratory of Evolutionary Systematics of Vertebrates, CAS (2011LESV007).

1 Shoshani J, Tassy P. Advances in proboscidean taxonomy \& classification, anatomy \& physiology, and ecology \& behavior. Quat Int, 2005, 126-128: 5-20

2 Tobien H, Chen G F, Li Y Q. Mastodonts (Proboscidea. Mammalia) from the late Neogene and early Pleistocene of the People's Republic of China, Part 1. Mainz Geowiss Mitt, 1986, 15: 119-181

3 Teilhard de Chardin P, Trassaert M. The proboscideans of SouthEastern Shanxi. Pal Sin Ser C, 1937, 13: 1-58

4 Chang H C. New materials of mastodons from the Yushe Basin, Shanxi (in Chinese). Vert PalAsiant, 1964, 8: 33-41

5 Tang Y J, Zong G F, Lei Y L, et al. Mamalian remains from the Pliocene of the Hanshui Rive Basin, Shanxi (in Chinese). Vert PalAsiant, 1987, 25: 222-235

6 Zong G F, Tang Y J, Lei Y L, et al. The Hanjiang Mastodont (Sinomastodon hanjiangensis nov. sp.) (in Chinese). Beijing: Beijing Science and Technology Press, 1989. 1-84

7 Zong G F. Note on some mammalian fossil of Yanyuan, Sichuan (in Chinese). Vert PalAsiant, 1987, 25: 137-145

8 Zong G F, Chen W Y, Huang X S, et al. Cenozoic Mammals and Environment of Hengduan Mountains region. Beijing: China Ocean Press, 1996. 1-279

9 Zhang X Y. Fossil mammals from the Early Pleistocene of Yongren, Yunnan (in Chinese). Vert PalAsiant, 1980, 18: 45-51

10 Chow M Z, Zhang Y P, You Y Z. Notes on some mastodons from Yunnan (in Chinese). Prof Pap Stratigr Paleonto, 1978, 7: 67-84

11 Chow M Z. New species of fossil Proboscidea from South China (in Chinese). Acta Paleontol Sin, 1959, 7: 251-258

12 Chen G F. Sinomastodon Tobien et al., 1986 (Proboscidea, Mammalia) from the Pliocene and Early-Middle Pleistocene of China (in Chinese). In: Wang Y Q, Deng T, eds. Proceedings of the Seventh Annual Meeting of the Chinese Society of Vertebrate Paleontology. Beijing: China Ocean Press, 1999. 179-187

13 Chow M C, Zhang Y P. Fossil Elephantoids From China (in Chinese). Beijing: Science Press, 1974. 1-74

14 Huang W B, Fang Q R. Wushan Hominid Site (in Chinese). Beijing: China Ocean Press, 1991. 1-230

15 Pei W Z. Carnivora, Proboscidea and Rodentia from Liucheng Gigantopithecus Cave and other caves in Guangxi (in Chinese). Memoirs of Institute of Vertebrate Paleontology and Paleoanthropology, 
Academia Sinica, No.18. Beijing: Science Press, 1987. 1-134

16 Jin C Z, Qin D G, Pan W S, et al. A newly discovered Gigantopithecus fauna from Sanhe Cave, Chongzuo, Guangxi, South China. Chin Sci Bull, 2009, 54: 788-797

17 Zheng S H. Jianshi Hominid Site (in Chinese). Beijing: Science Press, 2004. 1-412

18 Xu C H, Han K X, Wang L H. The Gigantopithecus fossils and associated fauna from west Hubei (in Chinese). Vert PalAsiant, 1974, 12: 293-306

19 Wang L H, Lin Y F, Yuan J R, et al. Mamalian fossils found in Northwest part of Hunan Province and their significance (in Chinese). Vert PalAsiant, 1982, 20: 350-358

20 Han D F, Xu C H, Yi G Y. Mammalian fossils of Quaternary from Bijiashan, Liuzhou, Guangxi (in Chinese). Vert PalAsiant, 1975, 13: 250-256

21 Pei W Z. On a new Trilophodon tooth from Wufeng of Hubei Province (in Chinese). Vert PalAsiant, 1965, 9: 209-216

22 Zhao Z R. Fossil mammals from Jiaoshan Wuming, Guangxi (in Chinese). Vert PalAsiant, 1980, 18: 299-303

23 Thasod Y, Ratanasthien B. New Proboscideans, Sinomastodon (Proboscidea, Mammalia) from Thailand. In: Wannakao L, Srisuk K, Youngme W, eds. The Proceeding of the International Conference on Geology, Geotechnology and Mineral Resources of Indochina, 2005. 594-599

24 Jin C Z, Liu J Y. Paleolithic Site- the Renzidong Cave, Fanchang, Anhui, China (in Chinese). Beijing: Science Press, 2009. 1-439

25 Wang Y, Jin C Z, Wei G B. First discovery of fossil Diplothrix (Muridae, Rodentia) outside the Ryukyu Islands, Japan. Chin Sci Bull, 2010, 55: 411-417

26 Ferretti M P. Anatomy of Haplomastodon chimborazi (Mammalia, Proboscidea) from the late Pleistocene of Ecuador and its bearing on the phylogeny and systematics of South American gomphotheres. Geodiversitas, 2010, 32: 663-721

27 Lister A. Evolution and taxonomy of Eurasian mammoths. In: Shoshani J, Tassy P, eds. Evolution and Palaeoecology of Elephants and Their Relatives. Oxford, New York, Tokyo: Oxford University Press, 1996. 203-213

28 Tassy P. Les Elephantoidea Miocènes du Plateau du Potwar, Groups de Siwalik, Pakistan. IIe partie: Choerolophodontes et gomphothères. Ann Paléontol, 1983, 69: 235-297

29 Tong H W. New materials of Mammuthus trogontherii (Proboscidea, Mammalia) of late Pleistocene age from Yuxian, Hebei (in Chinese). Quat Sci, 2010, 30: 307-318

30 Gohlich U B. Elephantoidea (Proboscidea, Mammalia) Aus Dem Mittel-Und Obermiozan Der Oberen Susswassermolasse Suddeutschlands: Odontologie Und Osteologie. Munchen: Muchner Geowiss,
1998. 1-245

31 Wang S Q, Deng T. The first Choerolophodon (Proboscidea, Gomphotheriidae) skull from China. Sci China Earth Sci, 2011, 54: 13261337

32 Osborn H F. Proboscidea. New York: The Am Mus Nat Hist Press, 1936. 1-802

33 Ferretti M P. A review of South American gomphotheres. New Mexico Nat Hist Sci Mus Bull, 2008, 44: 381-391

34 Gohlich U B. Order Proboscidea. In: Rossner G E, Heissig K, eds. The Miocene Land Mammals of Europe. Munchen: Verlag Dr. Friedrich Pfeil, 1999. 157-168

35 Prado J L, Alberdi M T. A cladistic analysis among trilophodont gomphotheres (Mammalian, Proboscidea) with special attention to the south American genera. Paleontology, 2008, 51: 903-915

36 Deng T. Chinese Neogene Mammal biochronlogy. Vert PalAsiant, 2006, 44: 143-163

37 Wang P X, Zhao Q H, Jian Z M, et al. Thirty million year deep-sea records in the South China Sea. Chin Sci Bull, 2003, 48: 2524-2535

38 Guo Z T, Ruddiman W F, Hao Q Z, et al. Onset of Asian desertification by $22 \mathrm{Myr}$ ago inferred from loess deposits in China. Nature, 2002, 416: 159-163

39 Deng T, Xue X X. Chinese Fossil Horses of Equus and Their Environment (in Chinese). Beijing: China Ocean Press, 1999. 1-153

40 An Z S, Kutzbach J E, Prell W L, et al. Evolution of Asian monsoon and phased uplift of the Himalaya-Tibetan Plateau since late Miocene times. Nature, 2001, 411: 62-66

41 Repenning C A. Quaternary rodent biochronology and its correlation with climatic and magnetic stratigraphies. In: Mahaney W C, ed. Correlation of Quaternary Chronologies. Norwich: Geobooks, 1984. $105-118$

42 Liu T S, Shi Y F, Wang R J, et al. Table of Chinese Quaternary stratigraphic correlation remarked with climate change (in Chinese). Quat Sci, 2000, 20: 108-128

43 Qiu Z X, Deng T, Wang B Y. Early Pleistocene Mammalian Fauna from Longdan, Dongxiang, Gansu, China (in Chinese). Paleontologia Sinca, New Series C, 27. Beijing: Science Press, 2004. 1-198

44 Teilhard de Chardin P, Piveteau J. Les mammifères de Nihowan (Chine). Ann Paléont, 1930, 14: 1-134

45 Qiu Z X. Nihewan fauna and Q/N boundary in China (in Chinese). Quat Sci, 2000, 20: 142-154

46 Wei G B, Hu S M, Yu K F, et al. New materials of the steppe mammoth, Mammuthus trogontherii, with discussion on the origin and evolutionary patterns of mammoths. Sci China Earth Sci, 2010, 53: 956-963

47 Chen G F. Remarks on the Stegodon from the Late Cenozoic of China (in Chinese). Vert PalAsiant, 2011, 49: 377-392

Open Access This article is distributed under the terms of the Creative Commons Attribution License which permits any use, distribution, and reproduction in any medium, provided the original author(s) and source are credited. 